\title{
The association of Coronavirus Disease-19 mortality and prior bacille Calmette-Guerin vaccination: a robust ecological evaluation using unsupervised machine learning
}

Nathan A Brooks

The University of Texas MD Anderson Cancer Center https://orcid.org/0000-0002-5111-6914

Ankur Puri

McKinsey \& Company, Inc.

\section{Sanya Garg}

McKinsey \& Company, Inc.

\section{Swapnika Nag}

McKinsey \& Company, Inc.

Noshir Kaka

McKinsey \& Company, Inc.

Rodney W. Zemmel

McKinsey \& Company, Inc.

Jacomo Corbo

QuantumBlack, a McKinsey company

Anas El Turabi

McKinsey \& Company, Inc.

Paul K. Hegarty

Mater Private Hospital

Ashish M. Kamat ( $\square$ AKamat@mdanderson.org )

The University of Texas MD Anderson Cancer Center

\section{Research Article}

Keywords: SARS-CoV-2, COVID-19, bacillus Calmette-Guerin, BCG, machine learning

Posted Date: June 15th, 2020

DOI: https://doi.org/10.21203/rs.3.rs-35340/v1

License: (1) This work is licensed under a Creative Commons Attribution 4.0 International License. Read Full License 


\section{Abstract}

Population-level data have suggested that bacille Calmette-Guerin (BCG) vaccination may lessen the severity of Coronavirus Disease-19 (COVID-19) prompting clinical trials in this area. Some reports have demonstrated conflicting results. We performed a robust, ecologic analysis comparing COVID-19 related mortality (CSM) between strictly selected countries based on BCG vaccination program status utilizing publicly available databases and machine learning to define the association between active BCG vaccination programs and CSM. Validation was performed using linear regression and country-specific modeling. CSM was lower for $80 \%$ of similarly clustered countries with a BCG vaccination policy for at least the preceding 15 years (BCG15). CSM increased significantly for each increase in the percent population over age 65 . The total population of a country and BCG15 were significantly associated with improved CSM. There was a consistent association between countries with a BCG vaccination for the preceding 15 years, but not other vaccination programs, and CSM.

\section{Introduction}

The severe acute respiratory syndrome coronavirus-2 (SARS-CoV-2) and the resulting clinical condition coronavirus disease (COVID-19) have caused a worldwide pandemic. There have been 4.8 million confirmed infections and 318,000 deaths worldwide as of May 19, 2020 [1] resulting in significant global and personal insecurity $[2,3]$. Mitigation of the pandemic requires a multifaceted strategy to reduce clinical morbidity/mortality, prevent disease spread, and, ultimately, the development of an effective vaccine. Many promising therapies for COVID-19 have demonstrated limited efficacy and the development of a vaccine will take time $[4,5]$. Supplementing the existing armamentarium for COVID-19 is therefore of the utmost importance.

The bacille Calmette-Guerin (BCG) vaccine has been administered to almost 4 billion people worldwide for almost 100 years for the prevention of tuberculosis (TB) [6]. Effectiveness for preventing pulmonary TB ranges from $40-60 \%$ and serious adverse events related to vaccination approach zero [7]. The BCG vaccine is associated with several favorable effects including a reduction in neonatal mortality from respiratory infections and sepsis [8] as well as in the treatment of bladder cancer [9]. When given in conjunction with anti-viral vaccinations including yellow fever and influenza, patients pre-treated with BCG have demonstrated reduced viremia, decreased levels of circulating cytokines associated with cytokine storms, and no difference in, or an improved, anti-viral antibody response [10.11]. These observations may be associated with a shift in the T-cell mediated response to pathogens, enhanced trained innate immunity, and/or an as yet undiscovered pathway [12]. However, they provide an immunologic foundation which suggests BCG vaccination is associated with clinically meaningful immunomodulatory function.

Hegarty and colleagues described the association of the crude case fatality rate (CFR) between 179 total countries with active BCG vaccination programs and those without such programs [13]. The CFR was 0.08 vs 34.8 per million for countries with and without BCG vaccination programs, respectively. In concert with the potential mechanisms described above, this work suggested that BCG vaccination might be associated with decreased COVID-19 severity. Since this time, several other authors have described similar trends 
suggesting that there is some degree of protection from severe COVID-19 infection, especially in elderly populations $[14,15]$. These observations and the underlying immunomodulatory potential of BCG have prompted several worldwide clinical trials including the BADAS trial in the US (www.bcgbadas.org) to evaluate the impact of BCG vaccination on the severity and rate of COVID-19 infection.

Employing unsupervised machine learning methods with adjustment for numerous variables and potential established confounders associated with mortality, we evaluated the association between covariates designated a priori including BCG vaccination programs and mortality associated with COVID-19 at a country level utilizing pre-specified inclusion criteria.

\section{Methods}

Countries were selected for model inclusion based on predefined criterion. Inclusion criteria included: more than 2,000 cases as of May 5,2020, population greater than 5 million, and land area greater than 1,000 km² (to exclude city-states with the potential for non-representative population densities). Exclusion criteria included countries where BCG program start year could not be ascertained.

All data leveraged originated from publicly available data sources (Supplementary Table 1). A set of potential disease related mortality drivers spanning seven domains - socio-economic, health system readiness, environmental, existing disease burden, demographics, vaccination programs, and response to the pandemic were selected a priori (Supplementary Table 2). COVID-19 specific mortality (CSM) was the primary outcome, defined as deaths related to COVID-19 per million population assessed 30 days after 100 reported cases.

Analysis was conducted in a stepwise manner. We sought to group countries into comparable clusters based on previously described CSM drivers. To do this, we first assessed the correlation amongst predetermined variables related to CSM (Supplementary Figure 1) which demonstrated substantial correlation between several explanatory variables. Therefore, exploratory factor analysis, an unsupervised machine learning method to reduce the original set of explanatory variables, was performed. The optimum number of factors were chosen using the scree plot (Supplementary Figure 2). An elbow was observed between 7 and 8 factors (Supplementary Tables 3a and 3b) [16]. Varimax rotation was used to maximize the loading of each variable on a single factor. From each factor group, variables were chosen as inputs for subsequent clustering and multiple regression analysis based on loading characteristics and expert consensus where loading values were similar. Given the large size of the first factor group, three variables were selected from the group. Population density was considered as a distinct group given low loading (below 0.3) value and included in addition to one other variable from group 6 . There was low variation of values for factors in group 7 thus no variables were included from this group. The variables selected included GDP per capita, population, population density, temperature (Celsius), percentage of the population above 65 years of age, and stringency index (SI) (a measure of country level interventions in response to COVID-19)[17].

Countries were then clustered utilizing the k-means algorithm, an unsupervised machine learning method [18]. The optimal number of clusters was determined using the average silhouette coefficient and Dunn 
Index (Supplementary Table 4, Supplementary Figure 3). Countries within a cluster were further segmented based on a categorical metrics related to BCG vaccination programs including if the country's BCG vaccination program was active and at least 40 years old or 15 years old based on prior works indicating a reduction of vaccination efficacy after a period of 15-40 years [19,20]. Deaths per million from COVID-19 thirty days after each country crossed 100 reported cases was compared for countries with currently active universal BCG vaccination programs and for either the preceding 40 or 15 years and those without such programs within a cluster. Countries within each cluster demonstrated lower coefficients of variation in testing rates compared to the whole population, and therefore normalization of testing rates was not performed.

To explore whether the findings were robust compared to alternate analytical approaches, we performed sensitivity analyses using linear regression models analyzing variables from each of the factor groups and CSM as the dependent variable. Additionally, age stratified CSM data 57 days after 100 cases (available for 7 countries for comparable periods) was analyzed for the population under 40 years compared with percent BCG coverage for the population 40 years or younger. Age less than 40 was used since the data for yearly BCG vaccine coverage for infants is reported most reliably from 1980 onwards [21]. The rate of and analytic strategy utilized for variables with missing information is presented in Supplementary Table 5. AP and AMK had full had full access to all the data in the study and take responsibility for the integrity of the data and the accuracy of the data analysis. The data that support the findings of this study are available from the corresponding author upon reasonable request. RStudio V 1.3.959 (Boston, MA, USA) was used for analysis.

\section{Results}

Of 212 countries/territories, 57 countries were included in analysis (Figure 1). Nine city states with insufficient land area or population and 141 countries with insufficient cases were excluded. Four countries met inclusion criteria but start dates for BCG vaccination programs were not available. China was excluded from the analysis as it was the first country to report widespread cases of the virus and therefore might have introduced a lead time bias.

Factor analysis resulted in the identification of six, distinct variables including GDP per capita, population, population density, temperature, percent population above 65 years, and stringency index (Table 1). Variables related to BCG administration were part of a distinct factor group. Countries within clusters had lower variation of both COVID-19 testing rates and Global Health Security Agenda (GHSA) scores, compared to the overall population. Two cluster solutions, with 6 and 9 clusters, demonstrated the highest scores (Dunn Index and Silhouette Score). Since findings were similar between the 6 and 9 cluster groups and cluster 9 only included 1 country in the 9-cluster solution (Supplementary Table 6), data for the remainder of the manuscript is presented from the six-cluster solution.

Deaths per million related to COVID-19 (CSM) was assessed 30 days after each included country reported 100 cases. Five of 6 clusters allowed division and comparison of CSM by the presence or absence of BCG vaccination programs for the preceding 15 years (BCG15) (Figure 2a). The remaining cluster composed 
exclusively countries with BCG vaccination programs (no comparison group-cluster 2). All 6 clusters allowed division and comparison of CSM by the presence or absence of BCG vaccination programs in the preceding 40 years (BCG40) (Figure $2 \mathrm{~b}$ ). Four of 5 clusters demonstrated lower mortality when they had BCG15 and 4 of 6 clusters demonstrated the same association with BCG40. For BCG40, specificity, clusters $1,3,5$, and 6 demonstrated improved CSM with hazard ratios of $0.03,0.01,0.17$, and 0.47 , respectively. Cluster 2 and 4 demonstrated worse CSM with hazard ratios of 2.43 and 2.24, respectively. The results from the 9-cluster analysis were similar (Supplementary Table 7). Granular data regarding clustering is presented in Supplementary Tables 8a/b.

Univariate regression analysis demonstrated that the percentage of the population above 65, total 2020 population, BCG15, average temperature, GDP per capita, Stringency Index, and BCG40 were significantly associated with CSM (Table 2). On multivariate analysis, only the presence of BCG15 (reduction of CSM by $71 \%$ (95\% Cl: 53 to $89 \%$ ), total population (for every 1 million person increase there was a $1 \%$ decrease in CSM ( $95 \%$ Cl: 0.53 to 1.47\%), and share of the population above 65 years (CSM increased by $10 \%$ for each percent increase in population over 65 (95\% Cl: 2 to $18 \%$ ) were shown to be significantly associated with CSM. Percent coverage metrics for vaccinations including RCV1 (Rubella), MCV1 (Measles) and OPV (Polio) were forced into the model and were not significantly associated with CSM.

Age stratified CSM for those under 40 years of age in relation to BCG coverage percentage for the same population was compared for 7 countries where the latest data was available (Table 3). Countries with no or low coverage for BCG vaccination in the population under 40, including the population between 30-39 and 20-29, had higher CSM for the same age groups, with the exception of Switzerland which had no reported COVID-19 related deaths in the 20-29 year age group.

\section{Discussion}

Using strict criteria designated a priori we have demonstrated an independent association between BCG vaccine administration programs active for the preceding 15 years and reduced CSM (71\% reduction). BCG15 was more strongly associated than BCG40 with CSM suggesting, as would be expected, improved efficacy for more recently administered vaccinations. It might also represent improved data reliability or vaccination administration for more recent programs. CSM was higher for populations over 65 years of age. CSM was lower for countries with lower total population which might suggest that transmission dynamics differ, testing rates are lower, that they or more able to mount a response, or an as yet identified factor is present [22]. OPV, MCV1, and RCV1vaccination status was not associated with decreased CSM suggesting that it is not the global presence of vaccination associated with CSM but specifically BCG vaccination.

Since we first described the association between BCG vaccination policies and CFR, several additional studies have corroborated this finding $[13,23]$. Sala et al. demonstrated that TB infection and BCG vaccination strategies were associated with decreased incidence and mortality related to COVID-19 [15]. Shet and colleagues demonstrated a 5.8-fold decrease in COVID-19 related mortality for populations with BCG vaccination[24]. These studies, including ours, are hampered by the quality of the data from which they derive their analysis as well as by the inability to adequately include and capture all potential confounding 
variables. The present analysis is strengthened by the comprehensive nature of the analysis not present in prior works as well as the a priori definition of input and outcome variables. The clinical validity of increased CSM for populations older than age 65 [25] has been well demonstrated. That this association was also determined in the machine learning models further strengthens the finding that BCG was associated with lower CSM.

Efficient contact tracing, isolation, and rapid testing, as part of a larger program of countermeasures, have proven effective at controlling SARS-CoV-2 outbreaks in areas such as China and South Korea. Neither the implementation of rapid contract tracing with targeted isolation, widespread testing, nor regional lockdowns have been as readily deployed in many countries [26,27]. Hensel et al. found that for countries with high testing rates, BCG vaccination no longer correlated with incidence [28]. However, in countries with current BCG vaccination policies and higher rates of testing, BCG vaccination remained significantly associated with reduced rates of CSM [28]. For Israeli adults aged 35-41 with symptoms suggestive of COVID-19, no difference was found in incidence for those born during BCG vaccination programs or those born just after they ended. This represented a young, 6000-person cohort with only 2 cases of severe disease [29] but did highlight the need for data quality and completeness. Our work is further strengthened by evaluating COVID19 mortality in 7 countries with complete vaccination data for the population under 40 where BCG vaccination continued to demonstrate an association with improved CSM.

The magnitude of the association between BCG and CSM must be taken in context with local responses to COVID-19. For example, in cluster 1, only South Korea (SK) had an active BCG vaccination program and the rates of CSM were lower in this cohort. This effect was again demonstrated for people in SK under the age of 40 . The lower rates of CSM in SK might represent BCG vaccination, the efforts of the public health department, or an unknown/unmeasured variable [30]. Similarly, in cluster 2, Ireland was the only country with an active BCG vaccination program, though with decreases in vaccination rates starting in 2005, but with higher levels of CSM which might more closely represent delay in taking COVID-19 measures [31]. In spite of such country specific possibilities, the general association of BCG vaccination status continue consistently demonstrated improved CSM.

We interpret our own findings with a cautionary note since there are numerous potential measured and unmeasured confounding variables including rates of BCG vaccination compliance, age at vaccination, potential strain differences among BCG vaccines, as well as regional variations within countries, a lack of a verified metric to measure country-level COVID-19 response effectiveness, no measures of health system capacity to provide effective, critical care, and other, as yet identified factors. We agree with the sentiments of the World Health Organization and caution against routine BCG vaccination for the prevention of COVID19 until prospective trials are completed. It is unclear if the protection from neonatal vaccination with BCG is transferrable to those receiving vaccination as an adult and how long such protection lasts. That is why some of the authors have initiated NCT04348370 (BADAS) trial in the US, joining other trials evaluating BCG administration for either COVID-19 prevention or disease severity reduction including: national clinical trial (NCT)04348370 (BADAS, USA), NCT04327206 (BRACE, Australia), NCT04328441 (BCG-CORONA, Netherlands), and NCT04350931 (Egypt). 
This analysis represents an attempt to utilize machine learning methods to address important questions in the field of medicine which might foster accelerated research in medicine and epidemiology.

\section{Conclusion}

For countries included in our analysis using an a priori, rigid entry criteria, the presence of an active BCG immunization program for the past 15 years and total population are associated with improved COVID-19 specific mortality while the share of the population over 65 years of age is associated with increased CSM. For the included countries BCG15 vaccination programs are associated with a $71 \%$ reduction in the risk for CSM independent of population, population density, temperature, share of population above 65 years, and the stringency index of each country. A reduction in CSM was observed in $80 \%$ of country clusters for BCG15. This ecological analysis provides the most robust data regarding the association of COVID-19 specific mortality and BCG vaccination programs. These findings suggest that BCG vaccination is one of many potential additions to our armamentarium in the fight to reduce mortality related to COVID- 19 .

\section{Declarations}

\section{Acknowledgements:}

The authors wish to acknowledge Ashna Kedia, Anuja Rege, Mohammad Nawaz Ahmad, Tanya Singh, Robert Muil, Sven Smit, Lieven Van Der Veken, Anaiya Kaka, Taera Kaka, Amit Chandra, Dr. Swati Piramal and Dr. Mahesh Balsekar for their contributions.

\section{Authorship Details}

All authors have approved the submitted manuscript, agree to be personally accountable for their own contributions, and agree to ensure that questions related to the accuracy or integrity of the work are appropriately addressed.

The following authors made substantial contributions to the concept and design of the work: NAB, AP, SG, $\mathrm{SN}, \mathrm{PH}, \mathrm{AMK}$

The Following authors contributed to the acquisition, analysis and interpretation of the data: AP, SG, SN, NK, RWZ, JC, AET.

The following authors drafted and revised the manuscript:

$\mathrm{NAB}, \mathrm{AP}, \mathrm{PH}, \mathrm{AMK}$

\section{Conflicts of Interest:}

The following authors report no conflicts of interest: NAB, AP, SG, SN, NK, RWZ, JC, AET, and PKH AMK is a consultant for Merck \& Co (Kenilworth, NJ, USA). 


\section{References}

1 Dong, E., Du, H. \& Gardner, L. An interactive web-based dashboard to track COVID-19 in real time. The Lancet Infectious Diseases 20, 533-534, doi:10.1016/S1473-3099(20)30120-1 (2020).

2 Wang, H.-y. et al. The psychological distress and coping styles in the early stages of the 2019 coronavirus disease (COVID-19) epidemic in the general mainland Chinese population: a web-based survey. PLoS One 15, e0233410, doi:10.1101/2020.03.27.20045807 (2020).

3 McKibbin, W. J. \& Fernando, R. The global macroeconomic impacts of COVID-19: Seven scenarios. Centre for Applied Macroeconomica Analysis Working Paper No 19/2020, doi:https://dx.doi.org/10.2139/ssrn.3547729 (2020).

4 Sanders, J. M., Monogue, M. L., Jodlowski, T. Z. \& Cutrell, J. B. Pharmacologic treatments for coronavirus disease 2019 (COVID-19): a review. JAMA 323, 1824-1836 (2020).

5 Dhama, K. et al. COVID-19, an emerging coronavirus infection: advances and prospects in designing and developing vaccines, immunotherapeutics, and therapeutics. Human Vaccines \& Immunotherapeutics, 1-7 (2020).

6 Oettinger, T., Jørgensen, M., Ladefoged, A., Hasløv, K. \& Andersen, P. Development of the Mycobacterium bovis BCG vaccine: review of the historical and biochemical evidence for a genealogical tree. Tubercle and lung disease 79, 243-250 (1999).

7 Roy, A. et al. Effect of BCG vaccination against Mycobacterium tuberculosisinfection in children: systematic review and meta-analysis. BMJ : British Medical Journal 349, g4643, doi:10.1136/bmj.g4643 (2014).

8 Aaby, P. et al. Randomized trial of BCG vaccination at birth to low-birth-weght cildren: Beneficial nnspecific efects in the nonatal priod? The Journal of Infectious Diseases 204, 245-252, doi:10.1093/infdis/jir240 (2011).

9 Sylvester, R. J., van der MEIJDEN, A. P. \& Lamm, D. L. Intravesical bacillus Calmette-Guerin reduces the risk of progression in patients with superficial bladder cancer: a meta-analysis of the published results of randomized clinical trials. The Journal of urology 168, 1964-1970 (2002).

10 Arts, R. J. et al. BCG vaccination protects against experimental viral infection in humans through the induction of cytokines associated with trained immunity. Cell host \& microbe 23, 89-100. e105 (2018).

11 Leentjens, J. et al. BCG vaccination enhances the immunogenicity of subsequent influenza vaccination in healthy volunteers: a randomized, placebo-controlled pilot study. The Journal of infectious diseases 212, 1930-1938 (2015).

12 Kleinnijenhuis, J. et al. Long-lasting effects of BCG vaccination on both heterologous Th1/Th17 responses and innate trained immunity. J Innate Immun 6, 152-158, doi:10.1159/000355628 (2014). 
13 Hegarty, P. K., Sfakianos, J. P., Giannarini, G., DiNardo, A. R. \& Kamat, A. M. COVID-19 and bacillus Calmette-Guérin: What is the link? European Urology Oncology, S2588-9311(2520)30049-30043 (2020).

14 Miller, A. et al. Correlation between universal BCG vaccination policy and reduced morbidity and mortality for COVID-19: an epidemiological study. MedRxiv (2020).

15 Sala, G. \& Miyakawa, T. Association of BCG vaccination policy with prevalence and mortality of COVID19. medRxiv (2020).

16 Bruin, J. UCLA: Statistical Consulting Group., <https://stats.idre.ucla.edu/stata/ado/analysis/> (2006).

17 Hale, T., Petherick, A., Phillips, T. \& Webster, S. Variation in government responses to COVID-19. Blavatnik School of Government Working Paper 31 (2020).

18 Charrad, M., Ghazzali, N., Boiteau, V. \& Niknafs, A. Determining the number of clusters using NbClust package. MSDM 2014, 1 (2014).

19 Nguipdop-Djomo, P., Heldal, E., Rodrigues, L. C., Abubakar, I. \& Mangtani, P. Duration of BCG protection against tuberculosis and change in effectiveness with time since vaccination in Norway: a retrospective population-based cohort study. The Lancet infectious diseases 16, 219-226 (2016).

20 Lord, J. et al. Economic modelling of diagnostic and treatment pathways in National Institute for Health and Care Excellence clinical guidelines: the Modelling Algorithm Pathways in Guidelines (MAPGuide) project. Health technology assessment (Winchester, England) 17, 1-192 (2013).

21 WHO-UNICEF. WHO vaccine-preventable diseases: monitoring system 2019 global summary. Geneva (CH): World Health Organization; 2019 https://apps.who.int/immunization_monitoring/globalsummary/timeseries/tswucoveragedtp3.html> (2019).

22 Dowd, J. B. et al. Demographic science aids in understanding the spread and fatality rates of COVID-19. Proceedings of the National Academy of Sciences 117, 9696-9698 (2020).

23 Redelman-Sidi, G. Could BCG be used to protect against COVID-19? Nature Reviews Urology, 1-2 (2020).

24 Shet, A., Ray, D., Malavige, N., Santosham, M. \& Bar-Zeev, N. Differential COVID-19-attributable mortality and BCG vaccine use in countries. medRxiv (2020).

25 Bhatraju, P. K. et al. Covid-19 in Critically III Patients in the Seattle Region - Case Series. New England Journal of Medicine 382, 2012-2022, doi:10.1056/NEJMoa2004500 (2020).

26 Kraemer, M. U. G. et al. The effect of human mobility and control measures on the COVID-19 epidemic in China. Science 368, 493-497, doi:10.1126/science.abb4218 (2020).

27 Cohen, J. \& Kupferschmidt, K. 1287-1288 (American Association for the Advancement of Science, 2020). 
28 Hensel, J. et al. Exercising caution in correlating COVID-19 incidence and mortality rates with BCG vaccination policies due to variable rates of SARS CoV-2 testing. medRxiv (2020).

29 Hamiel, U., Kozer, E. \& Youngster, I. SARS-CoV-2 Rates in BCG-Vaccinated and Unvaccinated Young Adults. JAMA, doi:10.1001/jama.2020.8189 (2020).

30 Song, J.-Y., Yun, J.-G., Noh, J.-Y., Cheong, H.-J. \& Kim, W.-J. Covid-19 in South Korea-challenges of subclinical manifestations. New England Journal of Medicine 382, 1858-1859 (2020).

31 Mills, G., Cullen, W., Moore, N. \& Foley, R. Making sense of publicly available data on COVID-19 in Ireland. medRxiv (2020).

\section{Tables}

Table 1: Simplified composition of 6 clusters included for analysis. 
$\begin{array}{llllll}\text { Cluster } 1 & \text { Cluster } 2 & \text { Cluster } 3 & \text { Cluster } 4 & \text { Cluster } 5 & \text { Cluster } 6\end{array}$

\begin{tabular}{|c|c|c|c|c|c|c|}
\hline $\begin{array}{l}\text { Number of } \\
\text { Countries }\end{array}$ & 4 & 7 & 7 & 7 & 12 & 20 \\
\hline $\begin{array}{l}\text { GDP for } \\
\text { Capita (lowest } \\
\text { last) }\end{array}$ & 3 & 1 & 2 & 6 & 4 & 5 \\
\hline $\begin{array}{l}\% \text { population } \\
>65 \mathrm{y} / 0 \\
\text { (lowest last) }\end{array}$ & 4 & 2 & 1 & 6 & 3 & 5 \\
\hline $\begin{array}{l}\text { Average } \\
\text { Temperature } \\
\text { (coldest last) }\end{array}$ & $3 *$ & 6 & $3^{*}$ & 1 & 5 & 2 \\
\hline $\begin{array}{l}\text { COVID } \\
\text { testing/million } \\
\text { at } 30 \text { cases } \\
\text { after first } 100 \\
\text { cases (lowest } \\
\text { last) }\end{array}$ & 2 & 1 & 4 & 6 & 3 & 5 \\
\hline $\begin{array}{l}\text { Coefficient of } \\
\text { Variation for } \\
\text { COVID } \\
\text { testing** }\end{array}$ & 60.8 & 29.1 & 76.3 & 62.2 & 69.7 & 96.9 \\
\hline $\begin{array}{l}\text { Stringency } \\
\text { Index (lowest } \\
\text { late) }\end{array}$ & $4^{*}$ & $4^{*}$ & 6 & $2^{*}$ & 1 & $2^{*}$ \\
\hline
\end{tabular}

$\begin{array}{llllll}\text { Overall GHSA } & 3 & 2 & 1 & 5 & 4 \\ \text { score (lowest } \\ \text { last) }\end{array}$

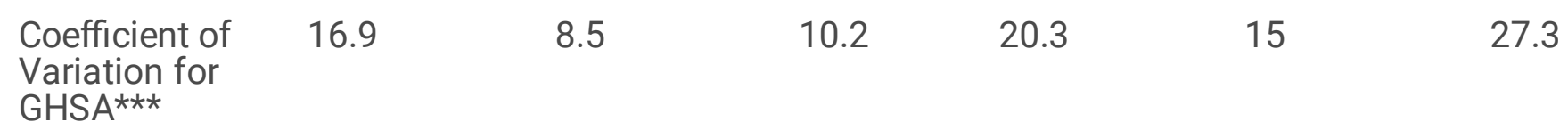

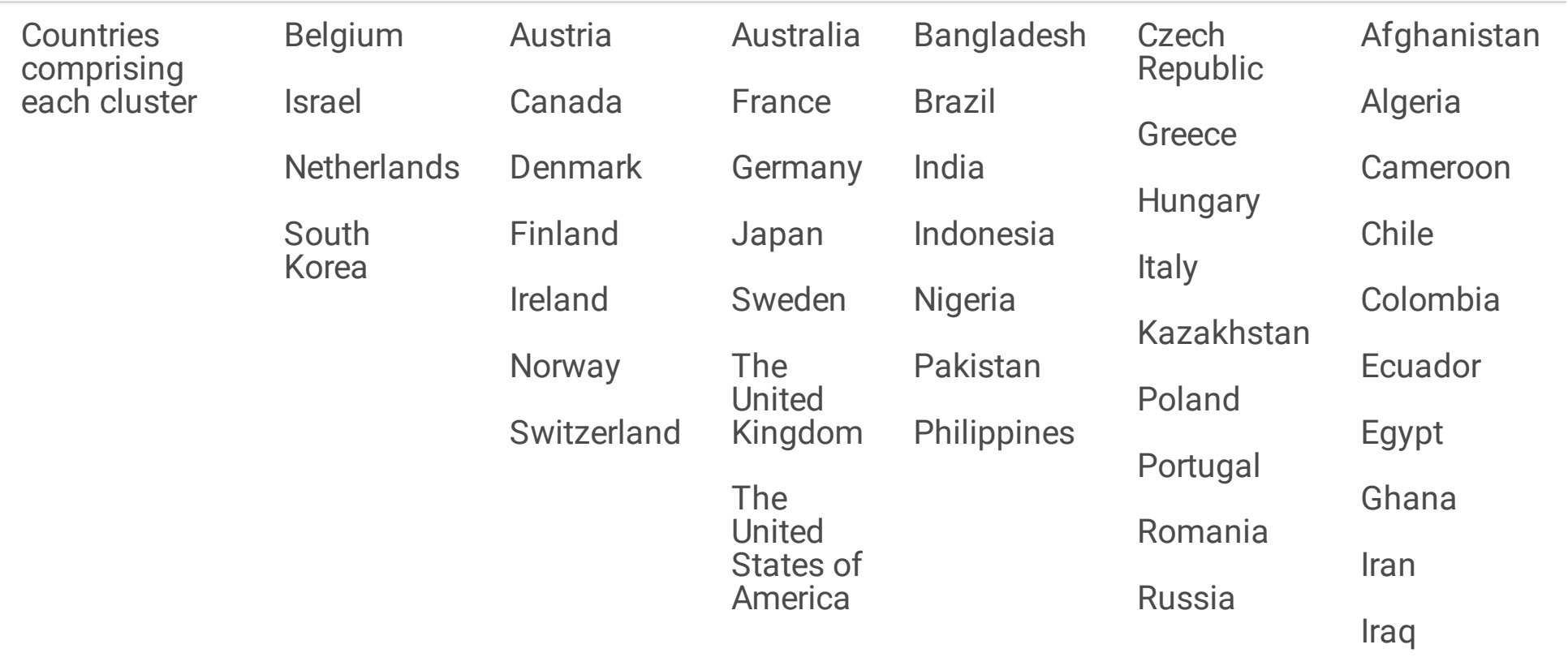




$\begin{array}{ll}\text { Serbia } & \text { Malaysia } \\ \text { Spain } & \text { Mexico } \\ & \text { Morocco } \\ & \text { Oman } \\ & \text { Peru } \\ & \text { Saudi } \\ & \text { Arabia } \\ & \text { South } \\ & \text { Africa } \\ & \text { Thailand } \\ & \text { Turkey } \\ & \text { Uzbekistan }\end{array}$

*represents tie in a category

${ }^{* *}$ coefficient of variation for the population Covid Testing/Million (30 days after 100 cases) was 103.5. Variation is lower in the clusters than the general population.

${ }^{\star * *}$ coefficient of variation for the population GHSA was 26.1. For all but cluster 6 , there is less variation in the clusters than the population.

Table 2: Results of linear regression analysis. The percentage of the population over 65 years of age was associated with higher rates of CSM such that for every percent increase in population over 65 years old, CSM increased by $10 \%$ (95\% confidence interval: $2 \%$ to $18 \%$ ). The total population of a country was associated with improved CSM (for every unit increase there was a 1\% decrease in CSM (95\% Cl: 0.53 to $1.47 \%)$. An active BCG vaccination program for the preceding 15 years was shown to reduce CSM significantly by $71 \%$ (95\% Cl: 53 to $89 \%)$. 
Univariate

Variable
Estimate $(95 \% \mathrm{Cl})$

(transformed from log)
Multivariate

Estimate $(95 \% \quad P$

Cl)

(transformed

from log)*

\begin{tabular}{|c|c|c|c|c|}
\hline $\begin{array}{l}\% \text { population over } 65 \text { years } \\
\text { old }\end{array}$ & $1.184 \pm 0.064$ & $P<0.001$ & $1.1 \pm 0.07$ & 0.009 \\
\hline Total 2020 population & $0.99 \pm 0.006$ & $P<0.001$ & $0.99 \pm 0.0047$ & 0.03 \\
\hline \multirow{5}{*}{$\begin{array}{l}\text { BCG vaccination in the } \\
\text { preceding } 15 \text { years }\end{array}$} & $0.1 \pm 0.054$ & $P<0.001$ & $0.29 \pm 0.18$ & 0.011 \\
\hline & $1 \pm 0.003$ & 0.78 & & $\begin{array}{l}\text { Not } \\
\text { significant }\end{array}$ \\
\hline & $0.913 \pm 0.04$ & $P<0.001$ & & $\begin{array}{l}\text { Not } \\
\text { significant }\end{array}$ \\
\hline & $1 \pm 0$ & $P<0.001$ & & $\begin{array}{l}\text { Not } \\
\text { significant }\end{array}$ \\
\hline & $0.97 \pm 0.022$ & 0.012 & & $\begin{array}{l}\text { Not } \\
\text { significant }\end{array}$ \\
\hline \multirow[t]{6}{*}{$\begin{array}{l}\text { BCG vaccination in the } \\
\text { preceding } 40 \text { years }\end{array}$} & $0.235 \pm 0.136$ & 0.001 & & $\begin{array}{l}\text { Not } \\
\text { significant }\end{array}$ \\
\hline & $0.988 \pm 0.008$ & 0.007 & & $\begin{array}{l}\text { Not } \\
\text { significant }\end{array}$ \\
\hline & $1.009 \pm 0.012$ & 0.16 & & $\begin{array}{l}\text { Not } \\
\text { significant }\end{array}$ \\
\hline & $1.009 \pm 0.013$ & 0.18 & & $\begin{array}{l}\text { Not } \\
\text { significant }\end{array}$ \\
\hline & $0.005 \pm 0.008$ & 0.21 & & $\begin{array}{l}\text { Not } \\
\text { significant }\end{array}$ \\
\hline & $0.0004 \pm 0.0006$ & 0.16 & & $\begin{array}{l}\text { Not } \\
\text { significant }\end{array}$ \\
\hline
\end{tabular}

*The antilog of all estimates. For example, when \% population above 65 yrs. increases by $1 \%$, the deaths/mn on an average increase by 1.10 times, i.e., $10 \%$ (with a $95 \%$ Cl of 1.02 to 1.18 or $2 \%$ to $18 \%$ ). Likewise, when a country has BCG coverage in the last 15 years, the deaths/mn decreases by 0.29 times, i.e., $71 \%$ (with a $95 \% \mathrm{Cl}$ of 0.11 to 0.47 or $89 \%$ to $53 \%$ )

Table 3: Analysis of CSM for populations aged $<40$ compared with the percent BCG vaccination rate in the same age group. Countries with lower rates of BCG coverage generally have higher rates of CSM suggesting that, even in a less vulnerable population, BCG vaccination is associated with improved CSM. 


\begin{tabular}{|c|c|c|c|c|c|c|}
\hline Countries & $\begin{array}{l}\text { CSM for } \\
\text { population } \\
<40 \text { years per } \\
\text { million } \\
\text { population } \\
<40 \text { years }\end{array}$ & $\begin{array}{l}\text { BCG } \\
\text { Coverage } \\
\% \text { under } \\
40 \text { years }\end{array}$ & $\begin{array}{l}\text { CSM for } \\
\text { population 20- } \\
29 \text { years per } \\
\text { million } \\
\text { population 20- } \\
29 \text { years }\end{array}$ & $\begin{array}{l}\text { BCG } \\
\text { Coverage } \\
\% \text { for age } \\
\text { groups } \\
\text { of } 20-29\end{array}$ & $\begin{array}{l}\text { CSM for } \\
\text { population } \\
30-39 \text { per } \\
\text { million } \\
\text { population } \\
\text { 30-39 years }\end{array}$ & $\begin{array}{l}\text { BCG } \\
\text { Coverage } \\
\% \text { for age } \\
\text { groups } \\
\text { of } 30-39\end{array}$ \\
\hline Sweden & 3.4 & 0 & 4.6 & 0 & 8.4 & 0 \\
\hline Italy & 2.3 & 0 & 1.2 & 0 & 6.3 & 0 \\
\hline Netherlands & 1.8 & 0 & 2.4 & 0 & 4.7 & 0 \\
\hline Switzerland & 1.2 & $\begin{array}{l}\text { Not } \\
\text { reported }\end{array}$ & 0.0 & 0 & 4.3 & $\begin{array}{l}\text { Not } \\
\text { reported }\end{array}$ \\
\hline $\begin{array}{l}\text { Czech } \\
\text { Republic }\end{array}$ & 1.1 & 74 & 0.8 & 78 & 2.6 & 98 \\
\hline Poland & 0.7 & 94 & 0.0 & 96 & 2.3 & 95 \\
\hline $\begin{array}{l}\text { South } \\
\text { Korea }\end{array}$ & 0.0 & 77 & 0.0 & 84 & 0.1 & 53 \\
\hline
\end{tabular}

Figures 


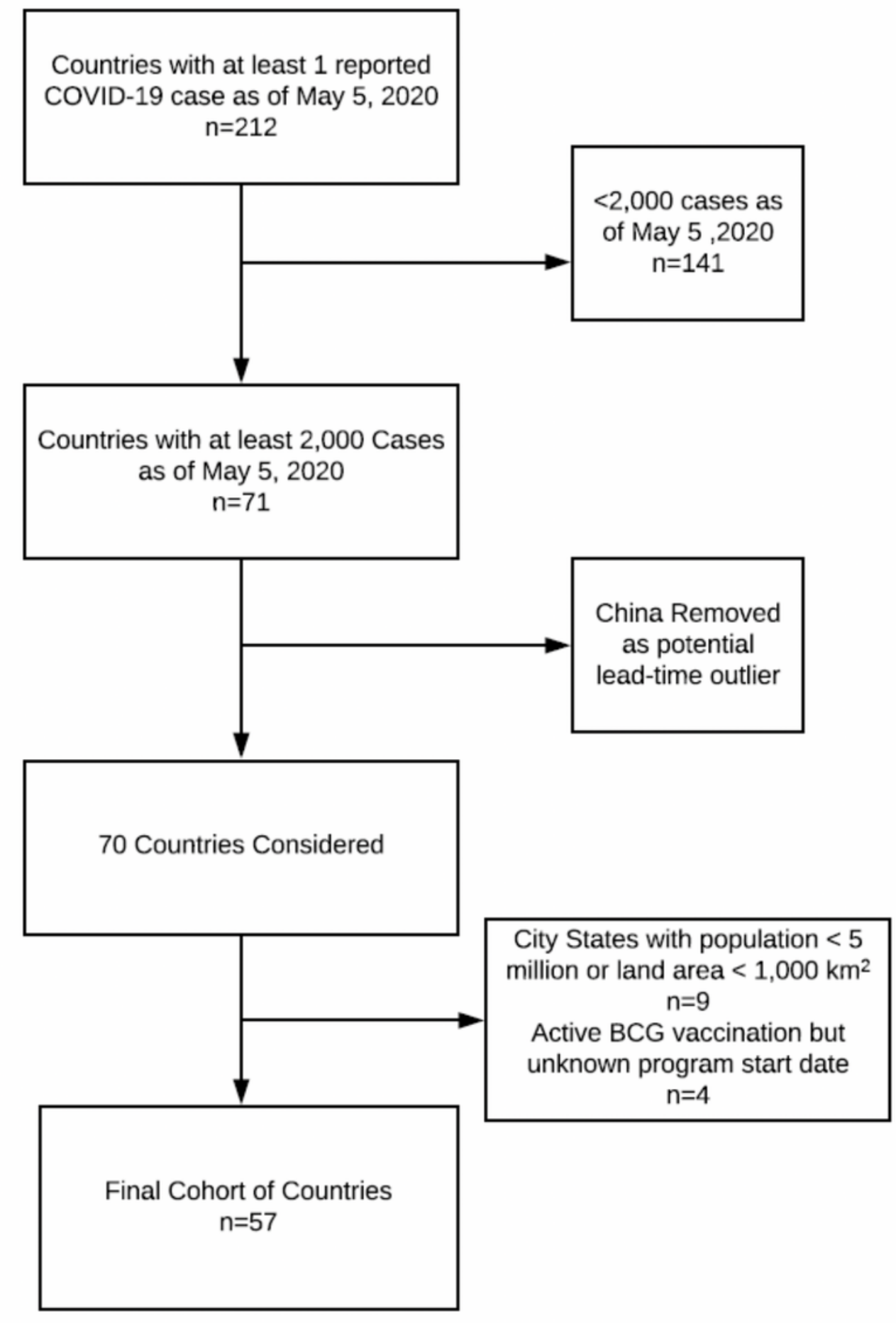

\section{Figure 1}

Consort diagram for the selection of countries included in evaluation. 212 countries and territories were initially screened with at least 1 case of COVID-19 as of May 5, 2020. Based on predetermined inclusion and exclusion criteria, 57 countries were included in the analysis. 


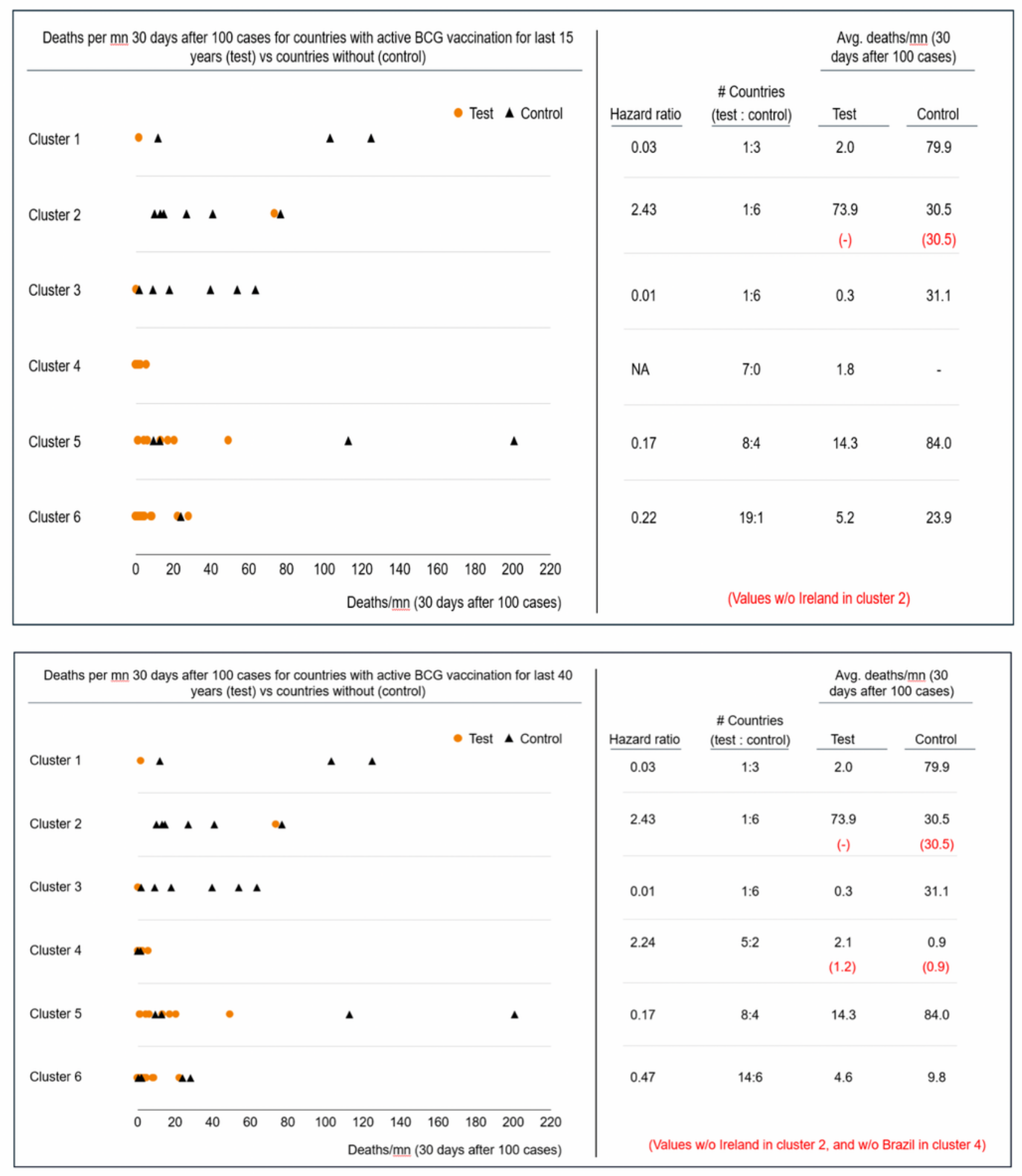

\section{Figure 2}

2a: Deaths per million 30 days after 100 cases were reached for countries with an active BCG vaccination program for the 15 years preceding the pandemic (Test) vs countries without BCG vaccination programs (Control). Cluster 4 contains no comparator and CSM was generally low. The results in cluster 2 are possibly driven by Ireland which has endured significant CSM among at risk populations. 2b: Deaths per million 30 days after 100 cases were reached for countries with an active BCG vaccination program for the 
40 years preceding the pandemic (Test) vs countries without BCG vaccination (Control). The results in cluster 2 are possibly driven by Ireland which has endured significant CSM among at risk populations

\section{Supplementary Files}

This is a list of supplementary files associated with this preprint. Click to download.

- SupplementaryTablesandFiguresSR.docx 